\title{
Dissecting the Determinants of Light Sensitivity in Amphioxus Microvillar Photoreceptors: Possible Evolutionary Implications for Melanopsin Signaling
}

\author{
Camilo Ferrer, ${ }^{1 \star}$ Gerardo Malagón, ${ }^{1 \star}$ María del Pilar Gomez, ${ }^{1,3}$ and Enrico Nasi ${ }^{2,3}$ \\ ${ }^{1}$ Department of Biology and ${ }^{2}$ Institute of Genetics, National University of Colombia, 111321 Bogotá, Colombia, and ${ }^{3}$ Marine Biological Laboratory, Woods \\ Hole, Massachusetts 02543
}

\begin{abstract}
Melanopsin, a photopigment related to the rhodopsin of microvillar photoreceptors of invertebrates, evolved in vertebrates to subserve nonvisual light-sensing functions, such as the pupillary reflex and entrainment of circadian rhythms. However, vertebrate circadian receptors display no hint of a microvillar specialization and show an extremely low light sensitivity and sluggish kinetics. Recently in amphioxus, the most basal chordate, melanopsin-expressing photoreceptors were characterized; these cells share salient properties with both rhabdomeric photoreceptors of invertebrates and circadian receptors of vertebrates. We used electrophysiology to dissect the gain of the light-transduction process in amphioxus and examine key features that help outline the evolutionary transition toward a sensor optimized to report mean ambient illumination rather than mediating spatial vision. By comparing the size of current fluctuations attributable to single photon melanopsin isomerizations with the size of single-channels activated by light, we concluded that the gain of the transduction cascade is lower than in rhabdomeric receptors. In contrast, the expression level of melanopsin (gauged by measuring charge displacements during photo-induced melanopsin isomerization) is comparable with that of canonical visual receptors. A modest amplification in melanopsin-using receptors is therefore apparent in early chordates; the decrease in photopigment expression - and loss of the anatomical correlates - observed in vertebrates subsequently enabled them to attain the low photosensitivity tailored to the role of circadian receptors.
\end{abstract}

\section{Introduction}

Electrophysiological examination of microvilli-bearing Joseph and Hesse cells in the neural tube of amphioxus (Branchiostoma floridae) has established that they are primary photoreceptors; their receptor potential, like that of rhabdomeric visual cells of arthropods and mollusks, is depolarizing and arises from the light-triggered opening of ion channels (Gomez et al., 2009). Moreover, photon absorption activates the phospholipase C (PLC) cascade (Angueyra et al., 2012), and the light-sensitive conductance displays a functional kinship to transient receptor potential channels, like those that underlie the light response in Drosophila and probably in other invertebrate microvillar photoreceptors (Pulido et al., 2012). The available supporting evidence, therefore, indicates that light-sensitive Joseph and Hesse cells of this chordate belong to the same lineage as the rhabdomeric photoreceptors of invertebrates (Nasi and Gomez, 2009).

A homolog of the photopigment melanopsin had been identified previously in amphioxus, its pattern of expression

\footnotetext{
Received June 28, 2012; revised 0ct. 19, 2012; accepted 0ct. 21, 2012.

Author contributions: M.d.P.G. and E.N. designed research; C.F., G.M., and M.d.P.G. performed research; C.F., G.M., M.d.P.G., and E.N. analyzed data; E.N. wrote the paper.

This work was supported by National Science Foundation Grant 0918930.

${ }^{*}$ C.F. and G.M. contributed equally to this work.

The authors declare no competing financial interests.

Correspondence should be addressed to Enrico Nasi, Cellular Dynamics Program, Marine Biological Laboratory, Woods Hole, MA 02543. E-mail: enasi@mbl.edu.

DOI:10.1523/JNEUROSCI.3069-12.2012

Copyright $\odot 2012$ the authors $\quad 0270-6474 / 12 / 3217977-11 \$ 15.00 / 0$
}

coinciding with the distribution of Joseph and Hesse cells (Koyanagi et al., 2005); in support for its involvement in the light response of these two classes of photoreceptors, the action spectrum measured electrophysiologically (Gomez et al., 2009) matches the spectral absorption of amphioxus melanopsin in vitro (Koyanagi et al., 2005). In higher vertebrates, melanopsin expresses, among others, in a subpopulation of retinal neurons [dubbed intrinsically photo-sensitive retinal ganglion cells (or ipRGCs)], which mediate nonvisual lightdependent functions, such as the regulation of circadian rhythms and the pupillary reflex (for review, see Berson, 2003; Peirson and Foster, 2006). On the basis of (1) sequence homology between melanopsin and the rhodopsins of invertebrate photoreceptors (Provencio et al.,1998), (2) the depolarizing response to light (Berson et al., 2002), and (3) the commonality of certain molecular and developmental markers (Arendt, 2003), it has been proposed that ipRGCs represent the remnants of the microvillar lineage of light-sensing cells in the vertebrate phylum (Arendt et al., 2002). Nonetheless, ipRGCs lack a rhabdomere, the defining structural feature of canonical microvillar receptors, and, in sharp contrast with their invertebrate counterparts, exhibit very low light sensitivity and uncommonly slow response kinetics (Berson et al., 2002; Do et al., 2009). These properties likely reflect the adaptation of ipRGCs to their role of reporting global changes of ambient illumination (e.g., night vs day) rather than mediating spatial vision, a function that calls for neither high sensitivity nor high temporal resolution (Do et al., 2009). 
Amphioxus has been classified by molecular phylogeny as the most basal extant chordate (Putnam et al., 2008) and has remained remarkably close to its ancestral condition (Schubert et al., 2006); therefore, its melanopsin-expressing photoreceptors provide a glimpse of early stages of the evolutionary history of this lineage of sensory cells among the deuterostomia (Nasi and Gomez, 2009) and can help elucidate the mechanistic basis of the pronounced functional divergence exhibited by its descendents in the vertebrates taxa. In the present study, patch-clamp recording in enzymatically dissociated Joseph and Hesse cells of amphioxus was used to dissect the biophysical determinants of their light sensitivity and establish a comparison with both invertebrate rhabdomeric photoreceptors and vertebrate circadian photoreceptors.

\section{Materials and Methods}

Cell isolation. Amphioxus (Branchiostoma floridae), both male and female, were obtained from Gulf Specimens Marine Laboratories and maintained in a seawater aquarium on a diet of marine phytoplankton and a $12 \mathrm{hlight} /$ dark cycle. Specimens were anesthetized by hypothermia, the rostral end was cut and pinned to a Sylgard-coated chamber, and the neural tube was excised. The tissue was then incubated with Pronase (750 $\mathrm{U} / \mathrm{ml}, 50 \mathrm{~min}$ at $22^{\circ} \mathrm{C}$; Boehringer Mannheim) dissolved in artificial sea water (ASW) (in mM: $480 \mathrm{NaCl}, 10 \mathrm{KCl}, 10 \mathrm{CaCl}_{2}, 49 \mathrm{MgCl}_{2}, 10 \mathrm{HEPES}$, and 5.4 glucose, $\mathrm{pH} 7.8$ ), followed by extensive washing in ASW supplemented with $4 \%$ fetal calf serum and mechanical trituration with a finebore fire-polished Pasteur pipette. The resulting cell suspension was plated into a perfusion chamber mounted on the stage of an inverted microscope (Carl Zeiss ICM-405 or Axiovert S-135). The coverslip bottom of the chamber was pretreated with Concanavalin-A to promote cell adhesion. Dissociated cells remain physiologically viable for several hours.

Electrophysiological recording. Patch pipettes were fabricated from borosilicate glass and fire polished before use. For whole-cell clamp, thin-wall borosilicate capillaries $(1.5 \mathrm{~mm}$ outer diameter, $1.1 \mathrm{~mm}$ inner diameter) were used, and the filling solution contained the following (in $\mathrm{mm}$ ): $100 \mathrm{KCl}, 200 \mathrm{~K}$-glutamate, $5 \mathrm{MgCl}_{2}, 5 \mathrm{Na}_{2} \mathrm{ATP}, 20 \mathrm{NaCl}, 1 \mathrm{EGTA}$, 300 sucrose, 10 HEPES, and 0.2 GTP, pH 7.3. Electrode resistance in ASW was 2-4 M $\Omega$; series resistance was compensated electronically (maximum residual error $<2 \mathrm{mV}$ ). For cell-attached single-channel recording, thick-wall capillaries were used instead ( $1.5 \mathrm{~mm}$ outer diameter, $0.75 \mathrm{~mm}$ inner diameter) and filled with ASW. Either a List EPC-7 or a Cairn Research Optopatch amplifier were used to measure membrane currents. Data were digitized with an analog-to-digital interface (DT3001 or DT9834; Data Translation), which served also to generate stimuli under the control of software developed in-house.

Light stimulation. Different optical stimulators were used in the two setups to generate light stimuli. Low-medium intensity illumination for eliciting responses in the physiological range was produced by one of two sources. (1) A tungsten-halogen lamp (Oriel), with collector and field lenses as well as a pinhole, restricted the illuminated region to a focused spot $(\sim 150 \mu \mathrm{m})$; a heat-absorbing filter $(\lambda>800 \mathrm{~nm})$ removed infrared (IR) light; a solenoid-driven shutter (Uniblitz; Vincent Associates) calibrated neutral density filters (Melles-Griot); and interference filters (Omega Optical) controlled the duration, intensity, and wavelength of stimulation. (2) A blue light-emitting diode (LED) (peak emission of 470 $\mathrm{nm}$ ), driven by a computer-controlled precision current pump, delivered a full-field light stimulus via a fiber optics bundle. This was positioned at a fixed distance above the recording chamber by a programmable micromanipulator (Eppendorf PatchMan). For high-intensity stimulation, necessary for evoking measurable pigment photoisomerization currents, two additional illuminators were coupled to the epifluorescence ports of the two microscopes, to stimulate the preparation via the microscope objective. One consisted of a $100 \mathrm{~W}$ mercury arc lamp (Carl Zeiss), electromechanical shutter, filters, and a liquid light-guide (Oriel). The other was a high-intensity LED (OptoFlash; Cairn Research) equipped with a $470 \mathrm{~nm}$ head. Light was measured with a radiometer (UDT Instru- ments) and, when appropriate, converted to equivalent effective photon flux via an in vivo calibration (Gomez and Nasi, 1994).

\section{Results}

\section{Quantum bumps}

A key parameter to characterize the performance of a lightsensing cell is the transduction gain, defined as the magnitude of the change in membrane current per absorbed photon. Microvillar photoreceptors from invertebrate eyes are capable of responding to individual photons with very prominent changes in membrane potential (Fuortes and Yeandle, 1964)_or in membrane current-that stand conspicuously above background noise. Vertebrate rods can also generate discernible singlephoton responses (Baylor et al., 1979). In such light sensors, therefore, a large-amplification factor in the signaling cascade triggered by the photoisomerization of one receptor molecule allows their performance to attain the quantum limit of sensitivity. As a result, stimulation with ever decreasing light intensities does not result in a corresponding monotonic decrease in response amplitude. Rather, at some point, discrete waves-also referred to as "quantum bumps"-are observed: these have a relatively fixed amplitude and stereotyped time course and occur with a frequency that reflects the rate of arrival of individual photons. In contrast, in several types of low-sensitivity photoreceptors, including vertebrate cones and ciliary invertebrate photoreceptors, the unitary response is undetectable over background fluctuations, and light responses to progressively dimmer stimuli become vanishingly small until they are lost in the noise.

Previous observations had indicated that, at very low light levels, membrane current of Joseph cells becomes noisy, characterized by rapid fluctuations (Gomez et al., 2009). Here we have examined the features of dim illumination responses at higher resolution, using a high sampling frequency $(20 \mathrm{kHz})$ and wide bandwidth $(5 \mathrm{kHz})$, and extended the analysis also to Hesse organs. Figure $1 A$ shows the effect of applying low-intensity illumination, lasting $400 \mathrm{~ms}$, to a Hesse cell voltage clamped at -50 $\mathrm{mV}$; beam attenuation was varied at $0.3 \mathrm{log}$ step increments. Rapid, inwardly directed current transitions were observed in response to illumination; although their fast kinetics precluded the use of heavy low-pass filtering - often making it arduous to attain a satisfactory signal-to-noise ratio $(\mathrm{S} / \mathrm{N})$ - it was evident that, as stimulating intensity was raised, the size and shape of such waves remained relatively invariant, whereas their frequency increased. In Figure $1 B$, the wave frequency is plotted as a function of photon flux for the low range of intensities; as a criterion to identify elementary waves, a peak amplitude twice that of the prestimulus noise was adopted. A least-squares fit shows that the relationship is approximately linear; the slight sublinearity at the highest intensity likely stems from missed counts attributable to wave overlap. With additional increase in light intensity, larger waves appeared, with variable amplitude and often a multipeaked shape, indicating that they result from the superposition of the smaller ones (Fig. 1C). These observations are consistent with the notion that each wave results from the absorption of a single photon. A more rigorous analysis would entail a frequency-ofseeing experiment (Fuortes and Yeandle, 1964), but this requires recording hundreds of trials, and we found that, during such a lengthy procedure, the cell sensitivity drifted and/or the baseline noise grew, compromising the reliable detection of the elementary events.

The size of the elementary waves was measured in several cells of both types at a holding potential of $-50 \mathrm{mV}$. Care was taken to 
A

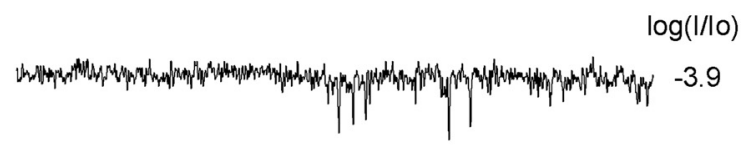

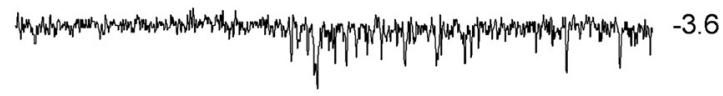

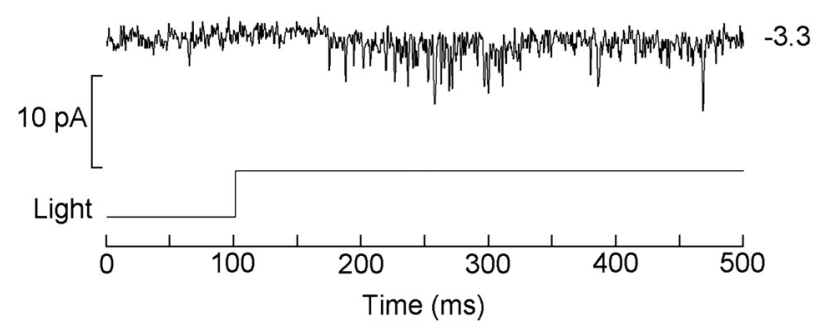

B

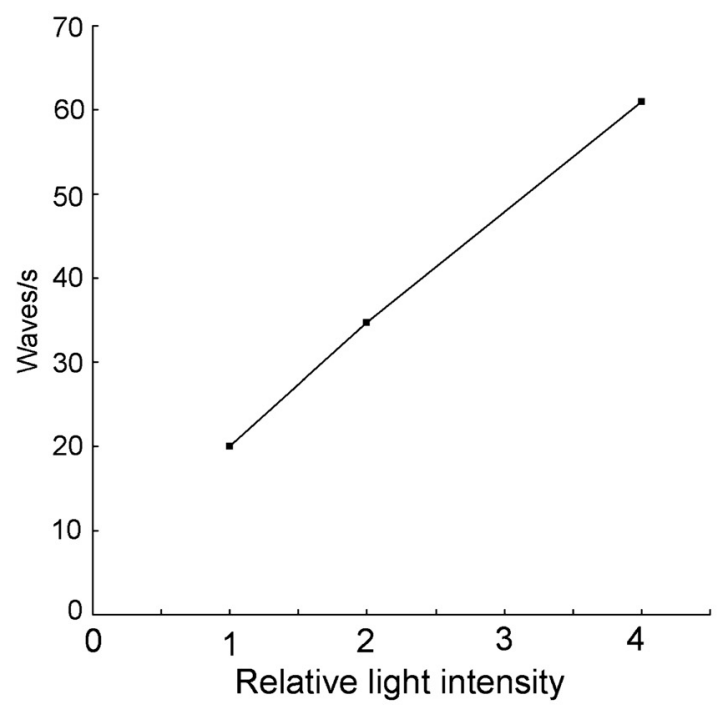

C

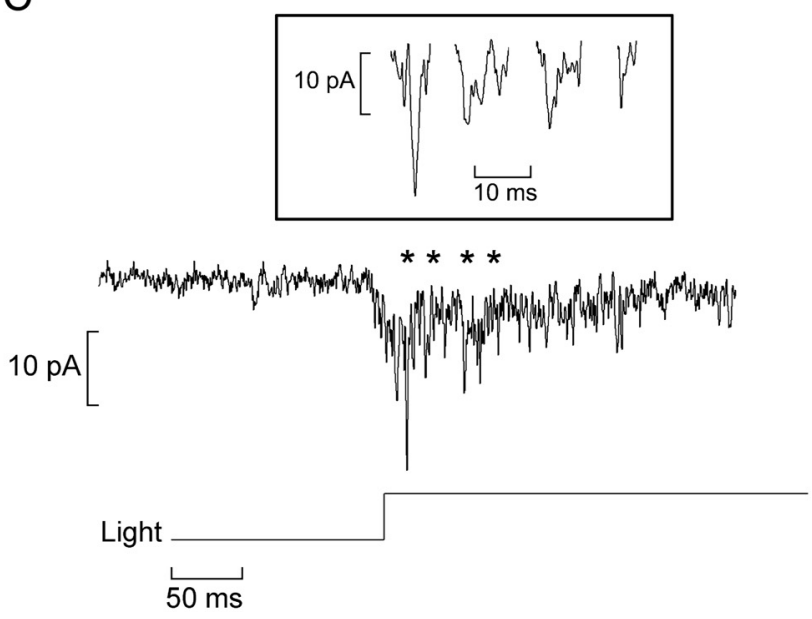

Figure 1. Discrete waves at low illumination intensities. $A$, Hesse cell voltage clamped at $-50 \mathrm{mV}$ was stimulated repetitively with a $400 \mathrm{~ms} s t e p$ of light, theintensity of which was increased at 0.3 log increments. Photostimulation elicited inward current waves of approximately constant amplitude and shape, but their frequency increased as a function of light intensity. Unattenuated light intensity $24.6 \times 10^{15}$ photons $\cdot \mathrm{cm}^{-2} \cdot \mathrm{s}^{-1} \cdot \boldsymbol{B}$, Wavefrequency plotted as a function of photon flux. C, With brighter lights, elementary waves overlap in time, giving risetolargerfluctuation with variable amplitude and multiple peaks (inset). Asterisks mark the stretches that are shown on expanded scale in the inset.
A
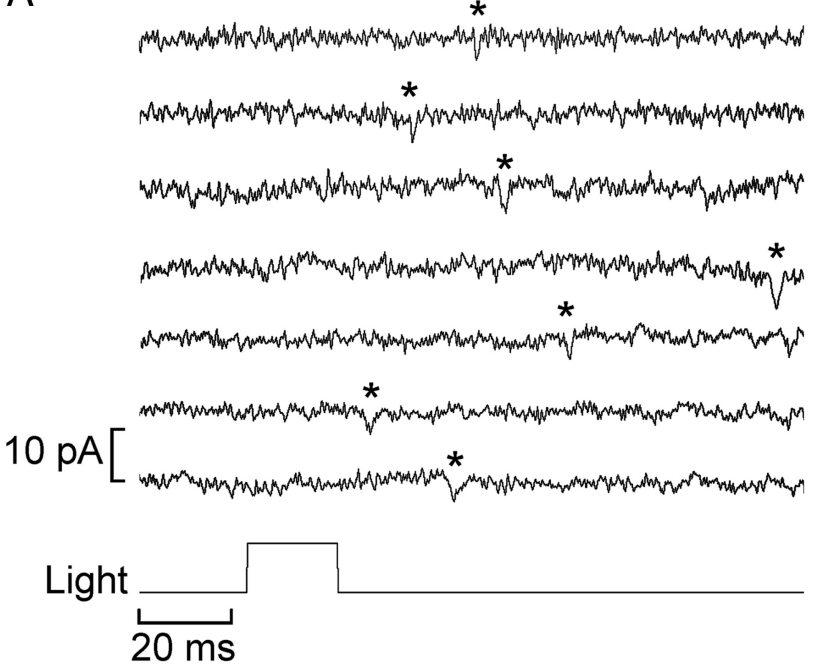

B

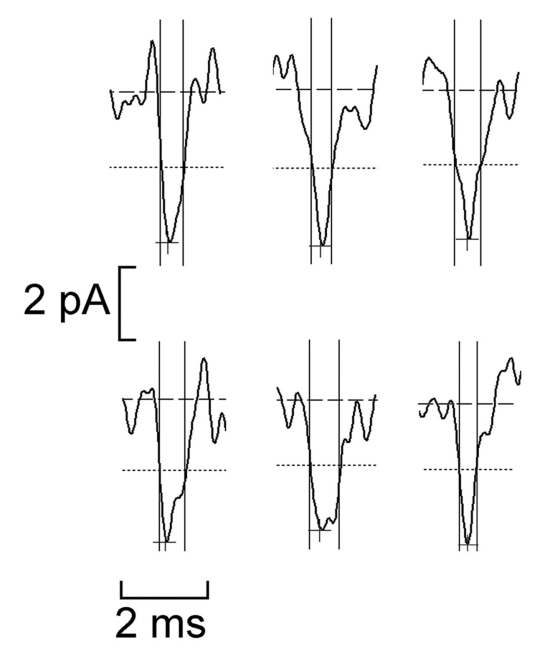

Figure 2. Size and speed of the light-evoked elementary waves. A, Stimulation of a Joseph cell with a repetitive flash of light of low intensity $\left(16.7 \times 10^{9}\right.$ photons $\left./ \mathrm{cm}^{-2}\right)$. Distinct quantum bumps (marked with the asterisks) could be identified and their amplitude measured. At this light intensity, a significant fraction of the trials produced no response (data not shown). $B$, Examples of elementary waves recorded in a Joseph cell. The dashed horizontal lines mark the average baseline current, whereas the cross and the dotted lines indicate the peak and the half-maximal amplitude, respectively. The vertical solid lines delimit the full-width at halfmaximal duration.

select waves devoid of multistep kinetics that may be indicative of multiple photon absorptions; for each cell, the mean amplitude of 12 waves was obtained. The protocol entailed the administration of either a $400 \mathrm{~ms}$ light step or repetitive brief flashes. Figure $2 \mathrm{~A}$ illustrates the latter case. The resulting average \pm SEM was $2.98 \pm 0.25 \mathrm{pA}(n=8)$ in Hesse cells and 2.79. $\pm 0.09 \mathrm{pA}(n=7)$ in Joseph cells. These values are approximately one-half to onethird of the size of the fluctuations described previously (Gomez et al., 2009), suggesting that those-obtained at considerably lower resolution - were likely responses to two to three photons. The difference across the two photoreceptor types was not statistically significant, indicating a similar transduction gain. The kinetics of the elementary responses is very rapid: Figure $2 B$ illustrates several examples of quantum bumps recorded in a Joseph cell; full-width at half-maximal duration (the time elapsed from the moment the wavelet attains $50 \%$ of the peak value to the moment it decays to the same level) is on the order of $1 \mathrm{~ms}$ (see 
vertical lines) and the full time course is $\sim 2 \mathrm{~ms}$, but some variability is evident. Although these observations are representative of most cells that were examined, occasionally some photoreceptors were found to generate consistently slower waves (5-8 ms); these presented no obvious morphological differences with respect to the others. The latencies of the quantum bumps exhibit a considerable dispersion, like in rhabdomeric photoreceptors, in which this factor has been shown to account for the shaping of the macroscopic photocurrent (Wong et al., 1980).

\section{Light-dependent channels}

Although the transduction gain in amphioxus is high enough to permit the detection of individual light quanta, such responses barely stand above background fluctuations, unlike invertebrate rhabdomeric receptors in which the $\mathrm{S} / \mathrm{N}$ for single-photon responses can be very large $(\mathrm{S} / \mathrm{N}=10-100)$. To dissect the determinants of this amplification, we turned to cell-attached recordings, with the aim of ascertaining whether single-channel currents activated by light can be recorded. We focused chiefly on Joseph cells, in which the microvilli-covered region-presumably comprising the photosensitive membrane-is exposed and often readily visualized. In contrast, in Hesse cells, the microvillar membrane abuts the pigmented accessory cell that completely engulfs it (Eakin and Westfall, 1962; Nakao, 1964; Ruiz and Anandon, 1991), making it inaccessible to a recording patch electrode. However, because in other photoreceptor types occasional light-dependent channels have been reported in the somatic membrane-albeit at very low density (Watanabe and Matthews, 1988)_few attempts targeted Hesse cells also.

After attaining a high-resistance seal, patches were tested with light stimulation; in most measurements, the pipette potential $\left(V_{\mathrm{p}}\right)$ was clamped at a fixed positive potential, i.e., hyperpolarizing the patch with respect to the rest of the cell membrane to increase the driving force on the local photocurrent. Singlechannel measurements proved quite challenging, exacerbated by the fact that the photocurrent is transient even with sustained stimulation and decays fully and rapidly to baseline without a discernible plateau (Gomez et al., 2009); therefore, at best, one can expect to record a brief burst of channel events. Figure $3 \mathrm{~A}$ shows an example obtained in a Joseph cell: $V_{\mathrm{p}}$ was set at +80 $\mathrm{mV}$, and a bright $100 \mathrm{~ms}$ flash was delivered, eliciting a vigorous burst of multichannel activity.

Because in cell-attached recording the intracellular potential is not clamped, the trans-patch voltage will change during the receptor potential, and one must rule out the possibility that the observed channel openings are triggered by voltage changes rather than being activated by the phototransduction cascade. To this end, current was also monitored in the dark as the command voltage applied to the pipette was changed over a range spanning $120 \mathrm{mV}$, which encompasses the changes in $V_{\mathrm{m}}$ that may occur during a photoresponse. No channel events were observed under these conditions, as shown in Figure $3 B$, indicating that the channel activity in $A$ is genuinely light dependent. Patches that exhibited any voltage-dependent openings in the dark were discarded.

In cell-attached recordings from responsive photoreceptors, a transient current is seen shortly after the onset of illumination; this has a prominent initial outward phase graded with light intensity, often followed by a smaller late inward phase. Such signals are evident also in patches devoid of channel activity and reflect the receptor potential picked up by the electrode via the coupling to the cell interior through the patch capacitance $\left(C_{\mathrm{p}}\right)$. Capacitative current is proportional to the time derivative of the voltage changes, and, in the present case, such contamination is
A

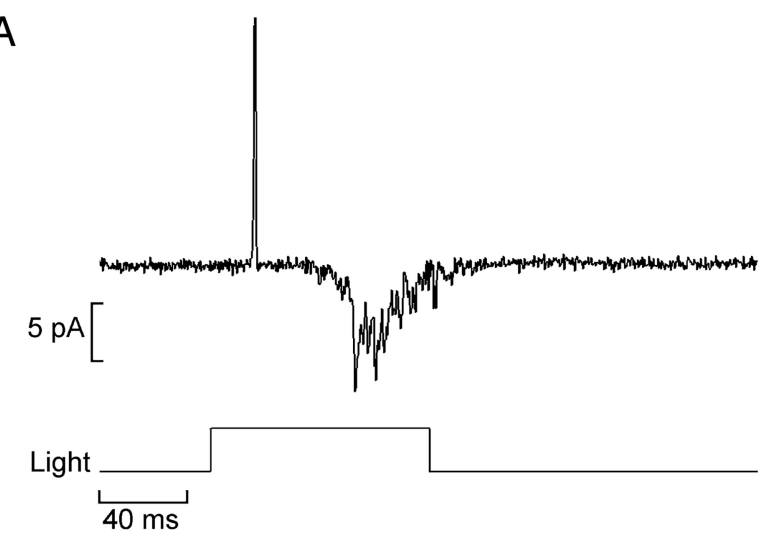

B

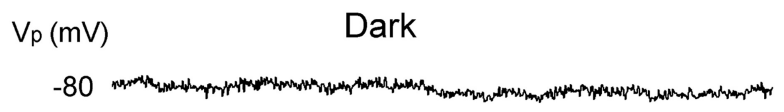

$-40$

0

$+40$

C

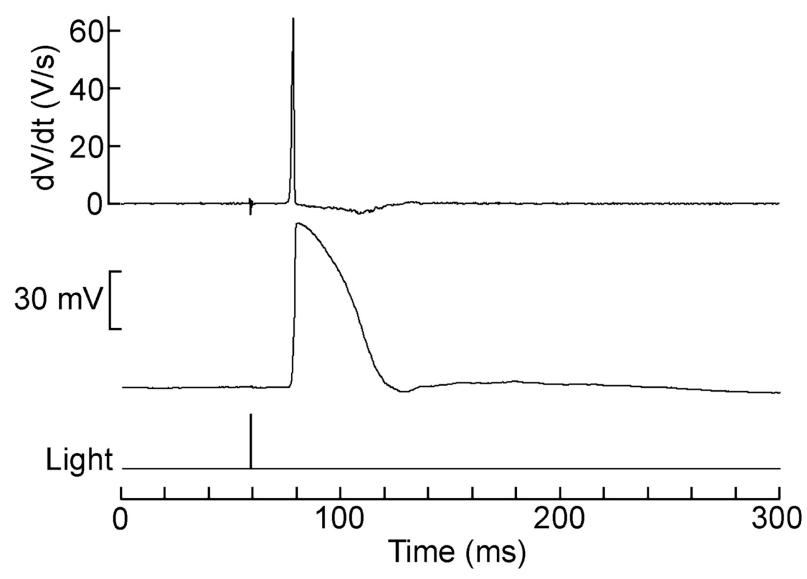

Figure 3. Cell-attached recording of light-activated unitary currents. $A$, Patch current evoked by a $100 \mathrm{~ms}$ flash $\left(13.3 \times 10^{14}\right.$ photons $\left./ \mathrm{cm}^{-2}\right)$ in a Joseph cell; the pipette was filled with $A S W$, and its $V_{p}$ was set at $+80 \mathrm{mV}$. Shortly after the outward spike, reflecting the depolarization induced by the light, a burst of inward channel currents is observed. $\boldsymbol{B}$, In the dark, application of depolarization to the patch over a wide range of voltages failed to activate channels. $C$, The speed of the rising phase of the receptor potential warrants the interpretation that the initial transient observed in on-cell recordings reflects the macroscopic light response picked up via capacitative coupling through the patch: the bottom trace shows membrane potential recorded intracellularly (current-clamp mode) in a Joseph cell; a saturating $1 \mathrm{~ms}$ flash $\left(6.3 \times 10^{13}\right.$ photons $\left./ \mathrm{cm}^{-2}\right)$ evoked a rapid transient depolarization. The top trace shows the time derivative of $V_{\mathrm{m}^{\prime}}$ highlighting the fact that, during the rising phase of the receptor potential, $d V / d t$ reaches $65 \mathrm{~V} / \mathrm{s}$; the falling kinetics is significantly slower ( $\min d V / d t=0.41 \mathrm{~V} / \mathrm{s})$.

not inconsequential: although on the basis of measurements of the surface area of a patch (Sokabe et al., 1991) $C_{\mathrm{p}}$ must necessarily be minute, on the order of 200-300 fF, the light response of amphioxus cells is uncommonly fast. Figure $3 C$ shows a receptor 
potential measured in current-clamp mode with the whole-cell configuration, together with the time derivative of the membrane voltage. During the rising phase, the slew rate can exceed $60 \mathrm{~V} / \mathrm{s}$, as the example illustrates. One can thus expect a capacitative spike with a peak amplitude that can exceed $10 \mathrm{pA}\left(I_{\mathrm{C}}=C_{\mathrm{p}} d V /\right.$ $d t)$. In contrast, the decay of the receptor potential is more sluggish, as one would anticipate not only from the slower phototransduction turn-off kinetics but also from the fact that, as the photoconductance shuts down, the membrane time constant will increase. As a result, the negatively directed second phase of $I_{\mathrm{C}}$ is smaller and sometimes altogether lost in the noise. The timing of the peak outward transient in cell-attached recordings closely matches the timing of the rising phase of the receptor potential in current-clamp measurements. To minimize confusion, single-channel traces were usually selected with openings that did not overlap with the initial transient. One should note that, on average, single-channel currents tend to have longer latencies than the macroscopic photocurrent, a phenomenon that has been attributed to the deformation of the membrane as it gets sucked into the recording pipette during seal formation, thus contributing an additional diffusional delay for the internal messenger (Bacigalupo and Lisman, 1983).

Light-dependent channel activity proved extremely variable across patches: many were silent to photostimulation; in others, only sporadic openings were observed, even with bright illumination, suggestive of the presence of a single light-dependent channel, as shown in Figure 4A. Again, voltage stimulation in the dark was ineffective $(B)$. On occasion, the stimulus elicited a massive activity akin to a pseudo-macroscopic photocurrent. Figure $4 C$ illustrates the latter case in a patch that produced multichannel current graded with light intensity, approaching a peak amplitude of nearly $40 \mathrm{pA}$. This unevenness in channel density likely reflects inconsistencies in the location of the recording pipette with respect to the microvilli, in which the highest density of transducing elements is expected: often, microvilli are not clearly discernible, and the cell provides no other morphological landmarks to guide electrode placement.

The lack of voltage-clamp conditions in cell-attached patches poses a significant challenge for determining the single-channel conductance because, during the light response, the driving force on the permeant ions is continuously changing, altering unitary current amplitudes. This difficulty can be circumvented by restricting the analysis to "late" channel openings, occurring when the receptor potential has primarily subsided; the capacitatively coupled signal discussed above provides a reference to this effect. By the same token, the probability of such events is necessarily low, so that very few patches could be found in which these requirements are fulfilled. Figure $4 D$ illustrates an instance in which the light-evoked activity occurred many tens of milliseconds after the stimulus onset and after the clearly biphasic $I_{\mathrm{C}}$, indicating that the light response had completed its course; the openings were very sporadic. The situation is more favorable when a large multichannel burst is elicited by light, as shown in Figure $4 E$ : in such a case, after the termination of the receptor potential, the residual activity still amounted to a substantial number of openings. Of course, even when $V_{\mathrm{m}}$ has fully repolarized to its resting level, such a value can only be estimated from intracellular measurements in other cells (approximately -55 $\mathrm{mV}$; Gomez et al., 2009) but is not known with accuracy; however, this ambiguity only contributes an additive constant to the current-voltage $(I--V)$ relationship, without altering its slope, and therefore has no repercussions for estimating single-channel conductance. Figure $4 \mathrm{~F}-\mathrm{H}$ illustrates examples in which these conditions were realized and the amplitude of individual openings could be resolved at different pipette potentials. The obtained mean \pm SEM unitary conductance was $32 \pm 3.1 \mathrm{pS}$ $(n=3)$. Although the transient nature of the amphioxus photoresponse precludes a systematic analysis of channel kinetics, pooling measurements of open times across different patches yielded an apparent mean value of $\sim 1 \mathrm{~ms}$ (no attempt to correct for missed events); as photostimulation intensity was raised, the opening frequency increased without discernible changes in open-state durations.

A second strategy to assess unitary conductance would be to record light-dependent single-channel currents in excised patches: because true voltage control is attained, the need to discard events occurring shortly after photostimulation is obviated. Experiments in other photoreceptors have shown that, after excision, patches of photosensitive membrane can retain their light responsiveness, albeit briefly (Ertel, 1990), indicating that the washout of the machinery coupling rhodopsin stimulation to channel gating is not instantaneous. This applies also to ipRGCs (Graham et al., 2008), although in that case, single-channel currents could not be resolved. To test isolated inside-out patches, cell-attached recordings were first performed as described above to ensure the exclusive presence of light-dependent channels. A puffer pipette was then lowered into the bath under IR visualization and positioned close to the target cell. After starting local perfusion with intracellular solution, the patch was excised and stimulated with light and/or with voltage. Figure $5 A$ shows the response of a freshly excised patch to a bright light stimulus; as expected, the capacitative spike-prominent in on-cell recordings - is missing, but a few inward channel openings are visible. Repetition of the stimulus at a different pipette potential produced a unitary conductance estimate of $30 \mathrm{pS}$, before irreversible loss of light sensitivity. Voltage ramps provide a convenient alternative to better exploit the brief temporal window during which light responsiveness is retained and can yield unitary conductance estimates even with a single sweep. Figure $5 B$ illustrates the channel activity evoked by light as an excised patch was gradually depolarized; two sweeps, each preceded by the onset of a light step, could be applied before responsiveness declined. Control ramps in the dark were completely devoid of activity. At various times during the ramp, unambiguous unitary transitions in current amplitude could be identified and measured, and the corresponding value of $V_{\mathrm{p}}$ was determined. The plot in $C$ shows the resulting $I-V$ relationship; a least-squares linear fit to the data points yielded an estimated single-channel conductance of $37 \mathrm{pS}$. One can conclude that, in Hesse and Joseph cells, the singlechannel currents activated by light are similar in amplitude and duration to those described in rhabdomeric invertebrate photoreceptors (Bacigalupo and Lisman, 1983; Nagy and Stieve, 1990; Nasi and Gomez, 1992).

\section{Early receptor current}

The quantum bump amplitude of Joseph and Hesse cells is comparable with that of melanopsin-using circadian receptors of mammals, but the overall photosensitivity of the amphioxus cells remains several orders-of-magnitude higher (Do et al., 2009; Gomez et al., 2009). A factor that could likely account for this discrepancy is a much higher level of expression of the photopigment. To assess such a possibility, we turned to a functional assay. Photoisomerization of rhodopsin, in both vertebrate and invertebrate species, is accompanied by a tiny charge translocation. Provided that the population of molecules synchronously undergoing the light-induced conformational change is massive 


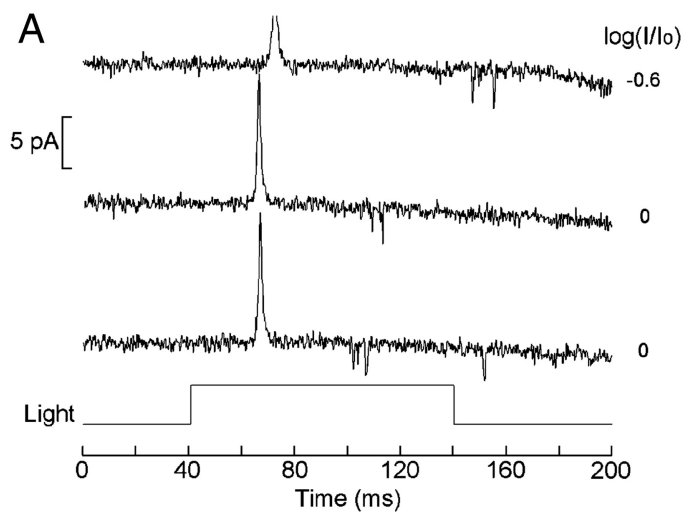

B

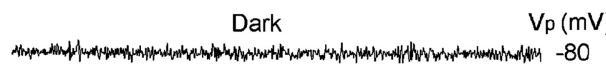

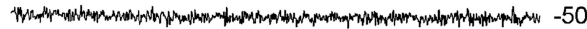

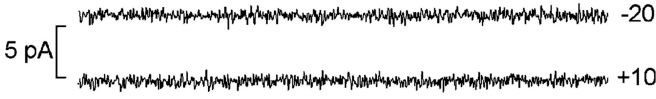

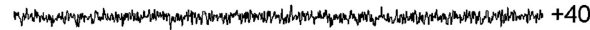
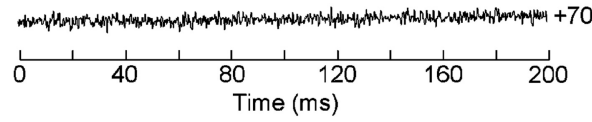

D

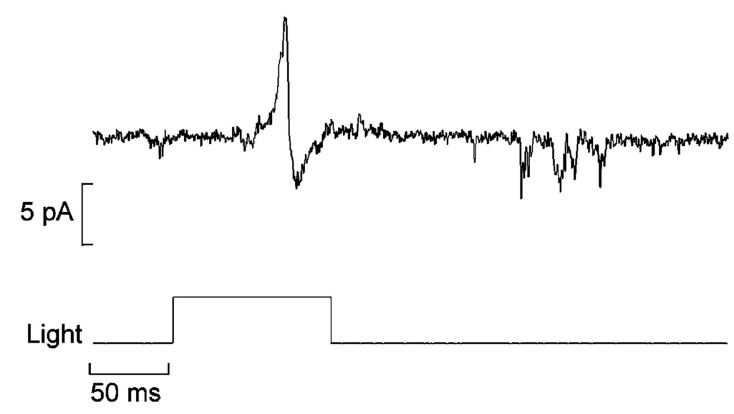

F

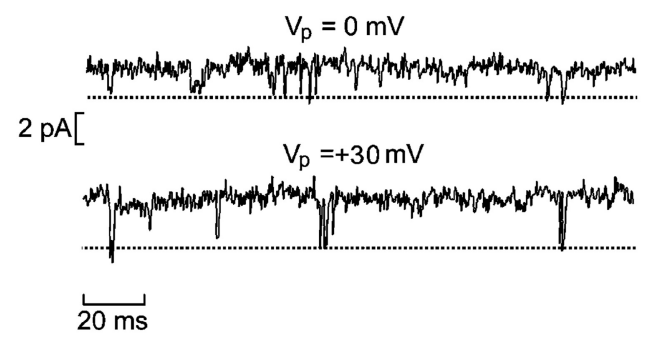

C

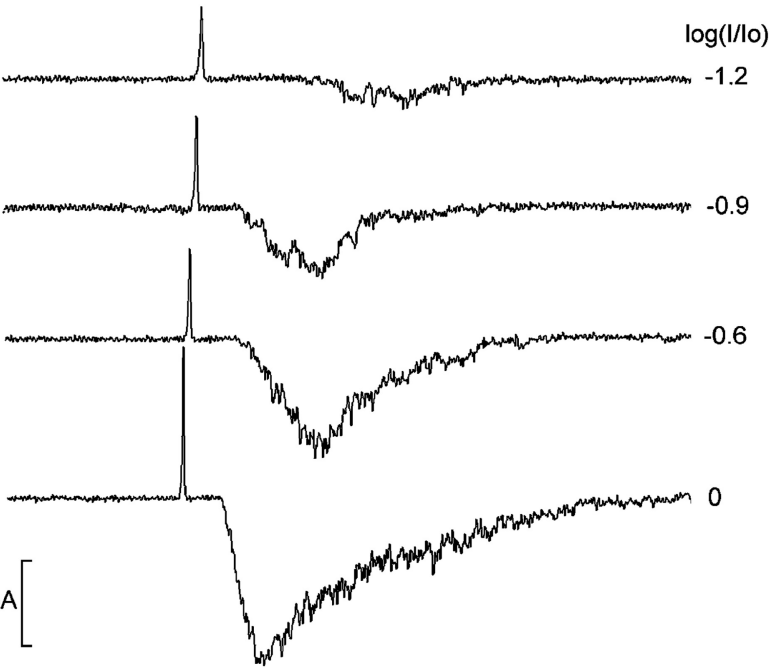

Light

$40 \mathrm{~ms}$
G

E
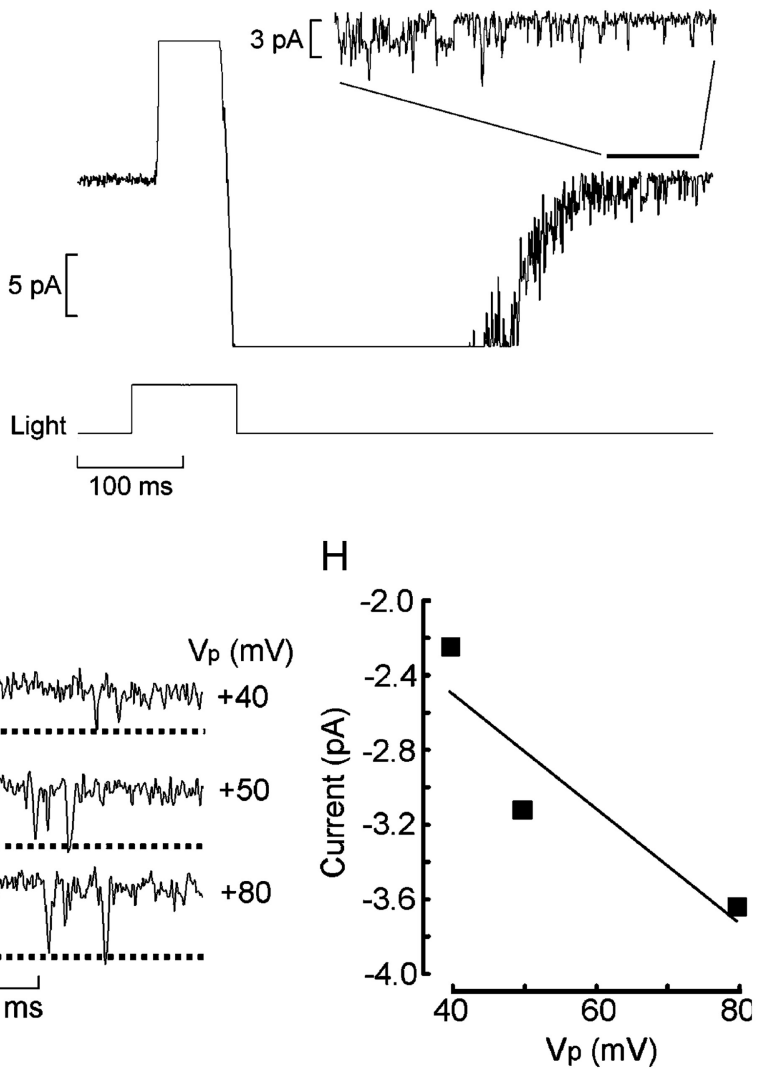

Figure 4. Variability in light-dependent channel density and use of late openings to gauge unitary conductance. $A, A$ patch in a Hesse photoreceptor producing a few isolated channel openings, although the cell was clearly responsive to light, as indicated by the presence of the capacitative transient; the attenuation factor is indicated near each trace $\left(V_{\mathrm{p}}=+50 \mathrm{mV}\right)$. Unattenuated light intensity $24.6 \times 10^{15}$ photons $\cdot \mathrm{cm}^{-2} \cdot \mathrm{s}^{-1}$. B, Voltage changes applied in the dark, spanning a range of $150 \mathrm{mV}$, failed to produce channel openings. $\boldsymbol{C}$, Massive, multichannel activity in a Joseph cell, evoked by stimulating light, the intensity of which was progressively increased, as indicated $\left(V_{p}=+80 \mathrm{mV}\right)$. The brightest flashes produced responses with a shape reminiscent of the macroscopic photocurrent of the cell. Unattenuated light intensity $11.4 \times 10^{15}$ photons $\cdot \mathrm{cm}^{-2} \cdot \mathrm{s}^{-1}$. D, Light-sensitive patch in which channel openings are entirely confined to a late interval after the clearly biphasic $I_{C}$, that is, after repolarization of the receptor potential (light, $6.2 \times 10^{12}$ photons $\cdot \mathrm{cm}^{-2} \cdot \mathrm{s}^{-1}$ ). $\boldsymbol{E}$, Activity in a patch containing numerous light-dependent channels. Inset, Expansion of the recording interval $400-500 \mathrm{~ms}$ after light onset reveals many clearly resolvable single-channel transitions. $F$, G, Late channel openings recorded at different pipette potentials in two patches (light, $5.8 \times 10^{13}$ and $6.1 \times 10^{15}$ photons $\cdot \mathrm{cm}^{-2} \cdot \mathrm{s}^{-1}$, respectively). $\boldsymbol{H}, I-V$ relationship for the events in $\mathbf{G}$. 
A
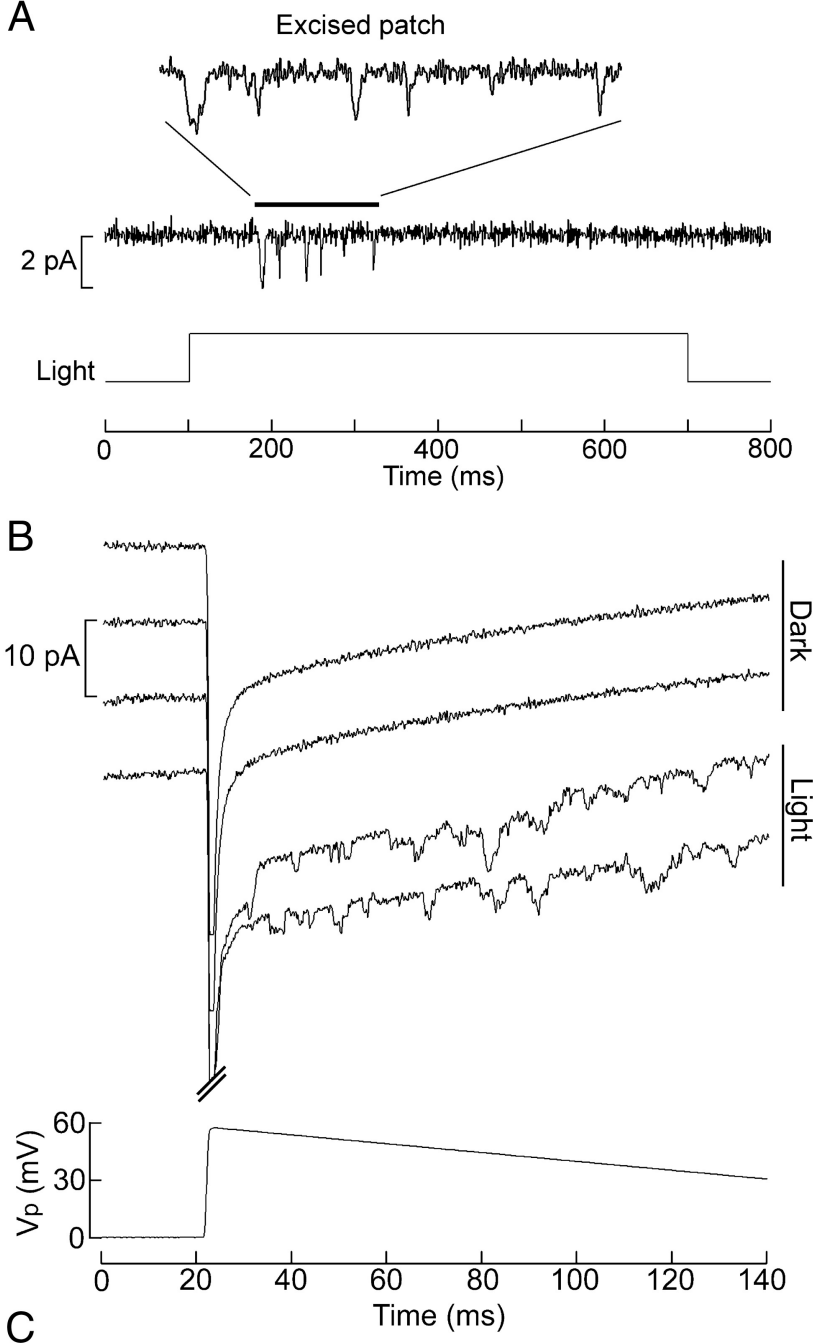

C

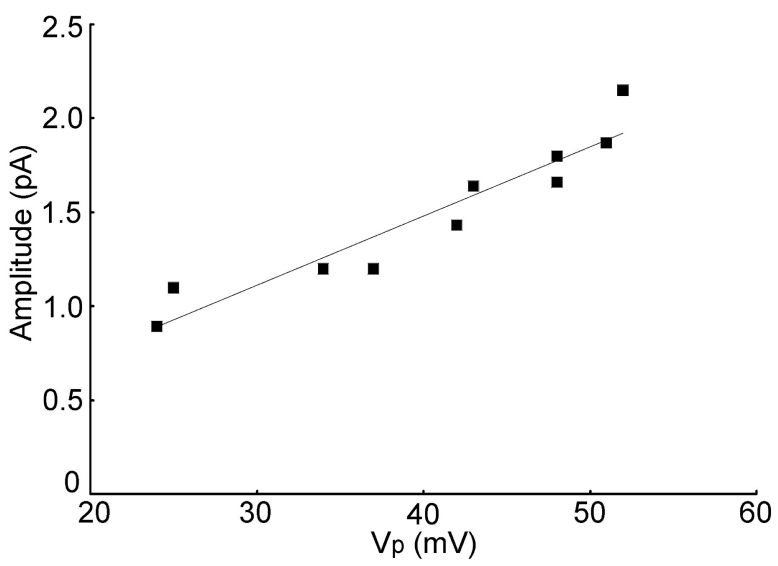

Figure 5. Excised patches retain phototransduction capabilities. A, Channel activity induced by a step of light in a patch that was excised, and the inner face was perfused with intracellular solution. $V_{\mathrm{p}}$ was set at $+50 \mathrm{mV}$. Notice the absence of the capacitative spike, as one would anticipate from the fact that the trans-patch voltage is under clamp. $\boldsymbol{B}$, Voltage ramps administered to an excised, perfused patch in either the dark or the presence of a light that was turned on $20 \mathrm{~ms}$ before the onset of the ramp. $C, I-V$ relationship for the single-channel currents of the traces in $\boldsymbol{B}$. The regression line has a slope corresponding to $37 \mathrm{pS}$. Light intensity, $24.6 \times 10^{15}$ photons $\cdot \mathrm{cm}^{-2} \cdot \mathrm{s}^{-1}$. enough to supply the necessary summation, this can produce a detectable transient voltage signal, known as the early receptor potential (ERP) (Cone, 1967). Under voltage clamp, the component of the charge movement normal to the plane of the plasma membrane can be recorded as a current with a predominant outward component, called the early receptor current (ERC). We used extremely bright flashes generated by either a mercury-arc illuminator or a high-intensity LED, to determine whether a measurable ERC is produced in amphioxus Joseph and Hesse cells. Figure $6 \mathrm{~A}$ illustrates the effect of such a stimulus in an isolated Joseph cell voltage clamped at $-50 \mathrm{mV}$ : a distinct outward hump with rapid kinetics occurs just before the onset of the inward photocurrent. $B$ of the same figure shows, in an expanded view, the responses elicited with increasing light intensities (at 0.6 $\log$ increments); the early transient only becomes visible with illumination beyond the levels at which the photocurrent has already attained a maximum amplitude. This rapid current does not desensitize like the photocurrent, so that repetition of an intense flash without interposing the necessary recovery interval leads to the loss of the latter, whereas the early component persists, as illustrated in Figure 6C.

The time course of an ERC is expected to be independent of the stimulating light (Hodgkin and O'Bryan, 1977; Makino et al., 1991), provided that the eliciting flash is brief (to minimize integration effects). This condition is fulfilled using the pulsed LED, which can deliver flashes of $1 \mathrm{~ms}$ with a sufficient number of photons for this purpose. As shown in Figure 6D, the shape of the rapid outward transient is indeed invariant with light intensity. The latency of the outward transient is extremely short: using the OptoFlash (to remove uncertainty about the kinetics of the electromechanical shutter) and measuring with respect to the direct light output monitor, it averaged $( \pm$ SEM) $609 \pm 38 \mu$ s $(n=10)$ for Joseph cells and $632 \pm 61 \mu \mathrm{s}(n=5)$ for Hesse cells; if one takes into account the time delay introduced by the analog lowpass Bessel filter at the cutoff frequency used $(5 \mathrm{kHz})$, these figures are further reduced by $\sim 500 \mu$ s, so the residual latency nearly vanishes in the noise under our conditions of acquisition. The decay of the transient when measured with the shortest effective flashes we could deliver $(1 \mathrm{~ms})$ is monoexponential, but cell-to-cell variability in time constant was encountered: although for most cells of both types $\tau=2 \mathrm{~ms}$, there were $\sim 15 \%$ of outliers, with a significantly slower decay approaching $10 \mathrm{~ms}$. It is conceivable that these may represent a separate subpopulation, although such cells did not present obvious morphological traits to distinguish them. In summary, the outward current evoked by bright flashes-with its brief latency, transient time course preceding the photoresponse, and imperviousness to adaptation-presents all the hallmarks of the displacement current accompanying photopigment isomerization.

Exploiting the ERC to gauge the total amount of photopigment requires a measurement of the charge displaced (i.e., the time integral of the current) when saturation is attained. Moreover, contamination by the late photocurrent-which, because of its rapid activation, can sometimes overlap with the tail of the ERC—-must be minimized. As illustrated in Figure 7A, the latter goal can be achieved by replacing extracellular $\mathrm{Na}$ with $\mathrm{N}$-methyl-D-glucamine (NMDG) and setting the holding potential between -25 and $-30 \mathrm{mV}$ : these are the conditions for reversal of the photocurrent (Pulido et al., 2012). Figure $7 B$ shows the average integral of the ERC in response to flashes of increasing intensity, for Joseph and Hesse cells. Both plots clearly approach saturation. The mean \pm SEM maximum charge displacement in the two cell types was $0.74 \pm 0.06 \mathrm{pC}(n=20)$ and $0.44 \pm 0.12 \mathrm{pC}$ 
A

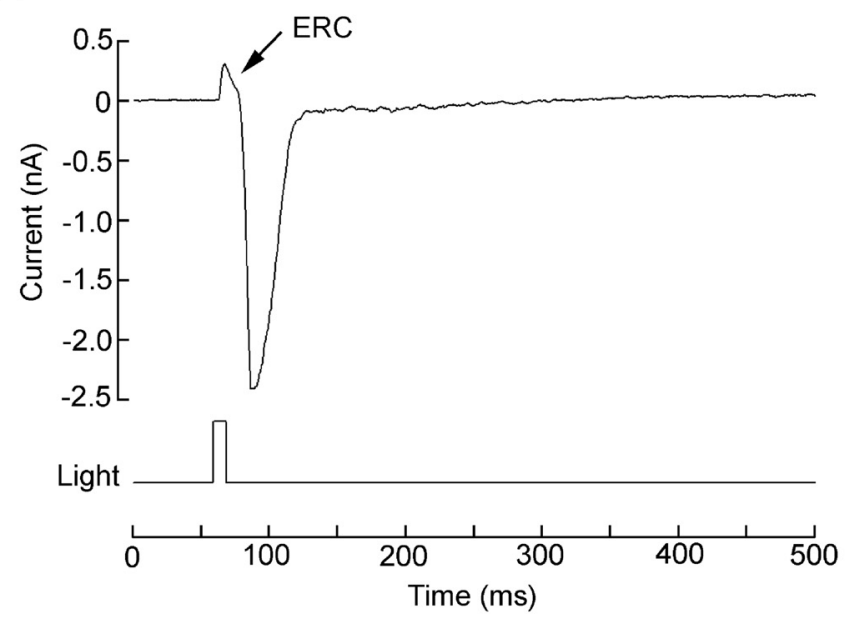

C

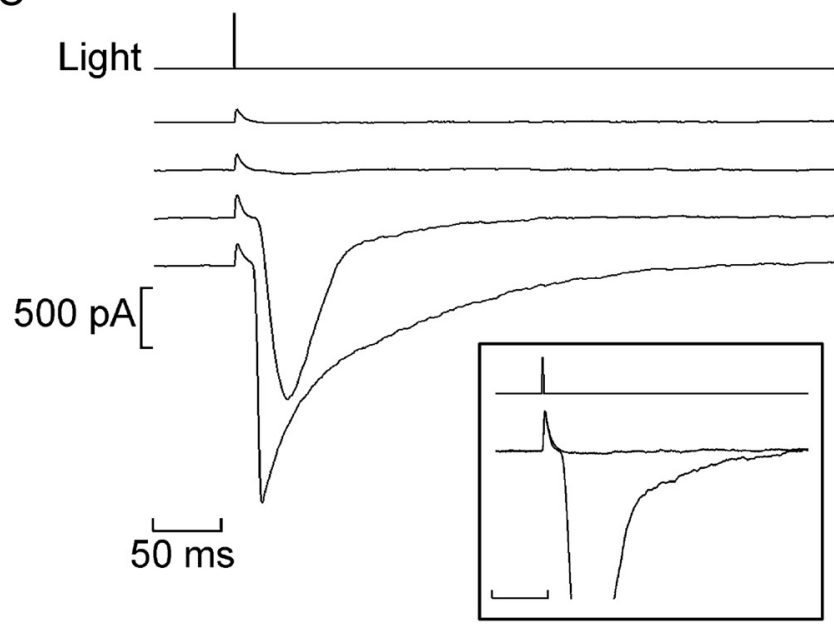

B

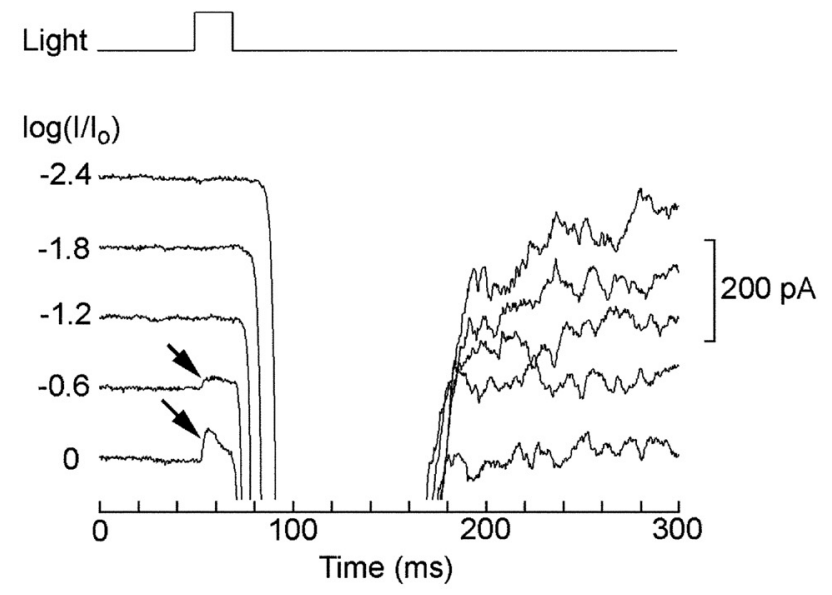

D
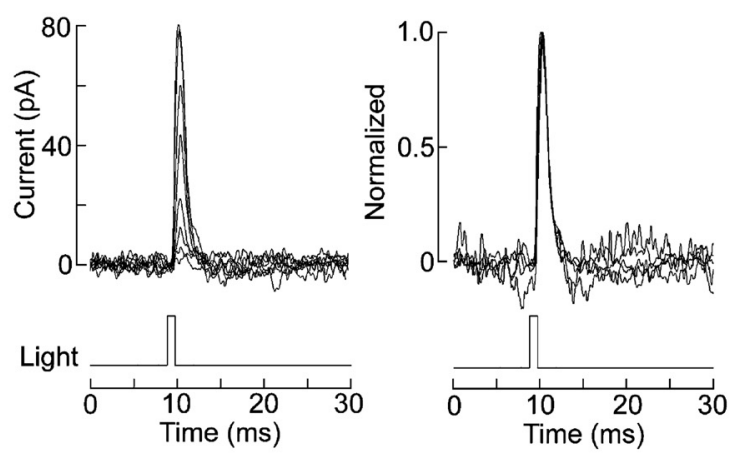

Figure 6. Melanopsin photoisomerization currents. $A$, Joseph cell stimulated with an intense flash $\left(4.42 \times 10^{17}\right.$ photons $\left.\cdot \mathrm{cm}^{-2} \cdot \mathrm{s}^{-1}\right)$ in control conditions $\left(V_{\mathrm{h}}=-50 \mathrm{mV}\right.$, ASW). A distinct, rapid outward transient precedes the onset of the photocurrent. $\boldsymbol{B}$, The amplitude of the early transient is graded with light within a range of intensities that saturates the photocurrent. Unattenuated light intensity, $17.6 \times 10^{17}$ photons $\cdot \mathrm{cm}^{-2} \cdot \mathrm{s}^{-1}$. C, Differential adaptation of the photocurrent. Repetition of an intense $1 \mathrm{~ms} \mathrm{stimulus}\left(15.9 \times 10^{14}\right.$ photons $\left./ \mathrm{cm}^{-2}\right)$ at $1 \mathrm{~min}$ intervals progressively desensitizes the photocurrent, whereas the early transient survives. Inset, Traces 1 and 3 superimposed and normalized. $\boldsymbol{D}$, The time course of the early transient is independent of stimulus intensity. Left, Superimposition of eight current traces recorded in a Joseph cell stimulated with $1 \mathrm{~ms}$ flashes of increasing intensity $\left(0.5-8 \times 10^{14} \mathrm{photons} / \mathrm{cm}^{-2}\right.$, at $\sim 2 \times$ increments). Right, Normalization shows the invariance of their shape. The two smallest responses were omitted to avoid excessive noise.

$(n=9)$, respectively. This difference attained statistical significance $(p<0.05, t$ test), indicating a larger total amount of photopigment in Joseph cells. This result implies that differences in the levels of melanopsin expression probably contribute-together with the screening action exerted by the companion pigmented cell-to the lower light sensitivity of Hesse cells compared with Joseph cells (Gomez et al., 2009).

It is instructive to compare the ERC of amphioxus with those of visual receptors of invertebrates, in which the photopigment is known to be packed at high density in the plasma membrane. Figure $7 C$ shows traces recorded under similar conditions in a Joseph cell, a rhabdomeric photoreceptor from Lima scabra, and a ciliary photoreceptor from Pecten irradians; these cells have comparable dimensions and membrane capacitance (Nasi, 1991a; Gomez and Nasi, 1994). The peak amplitude of the ERC is rather similar for all three cell types. Finally, in the bar graph of Figure $7 D$, the average saturating charge displacement obtained by integration of the ERC is compared across the two classes of amphioxus photoreceptors and the two invertebrate visual cells. Although the figures are undoubtedly lower in amphioxus, dif- ferences are confined within a twofold to fourfold range, implying that melanopsin expression level in amphioxus is still very high (see Discussion).

\section{Discussion}

Joseph and Hesse cells of amphioxus, with their melanopsinbased, PLC-using phototransduction cascade (Koyanagi et al., 2005; Gomez et al., 2009; Angueyra et al., 2012) and microvillar light-sensitive membrane (Eakin and Westfall, 1962; Nakao, 1964; Ruiz and Anandon, 1991), share key features with rhabdomeric visual receptors of invertebrates and circadian lightsensing cells of vertebrates (Koyanagi et al., 2005; Graham et al., 2008; Koyanagi and Terakita, 2008), two classes of photoreceptors that are now thought to descend from a common ancestor (Arendt, 2003). Nonetheless, some conspicuous differences distinguish these two groups of light sensors and numerous questions remain, concerning the divergence of ipRGC structural and functional features from those of canonical rhabdomeric photoreceptors: for example, the absence of discernible microvilli, the slow kinetics, and the greatly reduced light sensitivity. Enlisting 
A

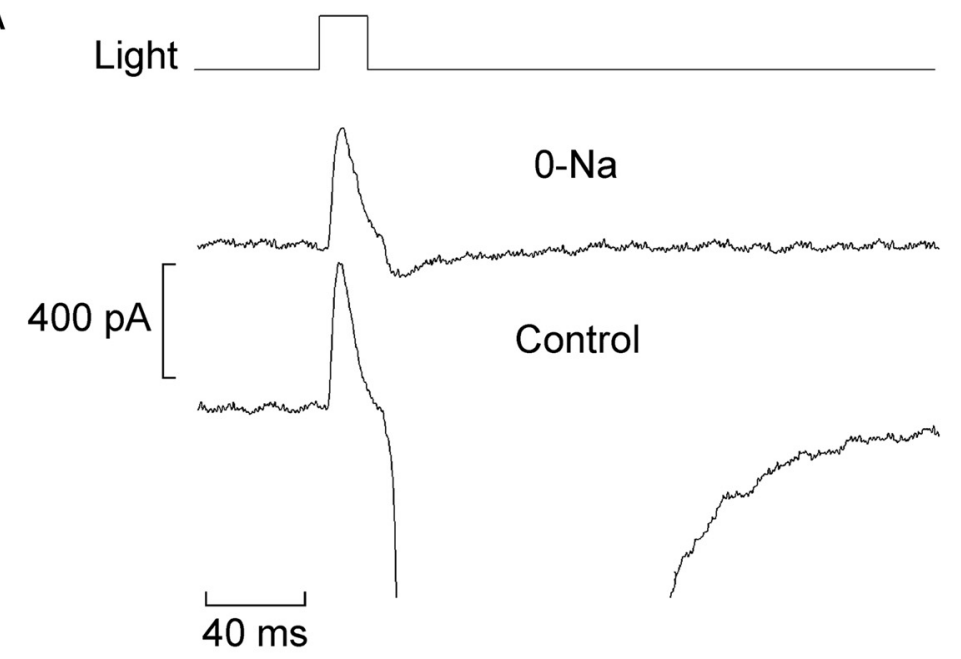

C

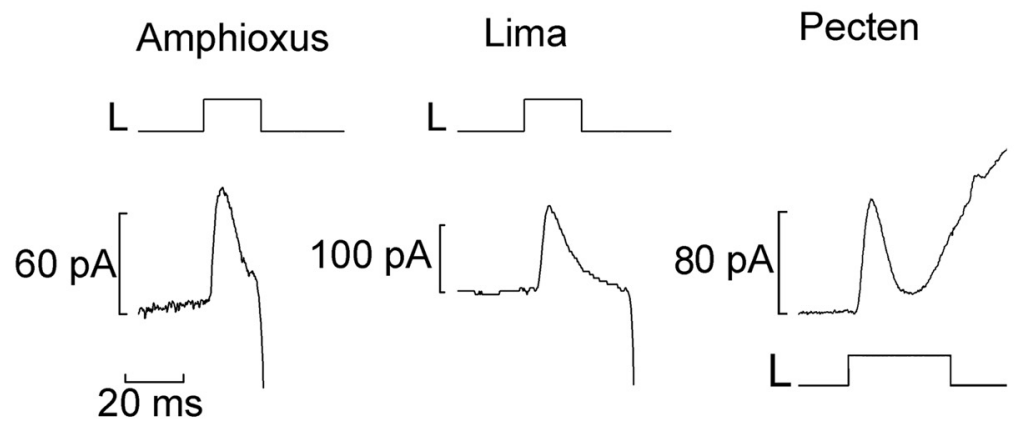

B

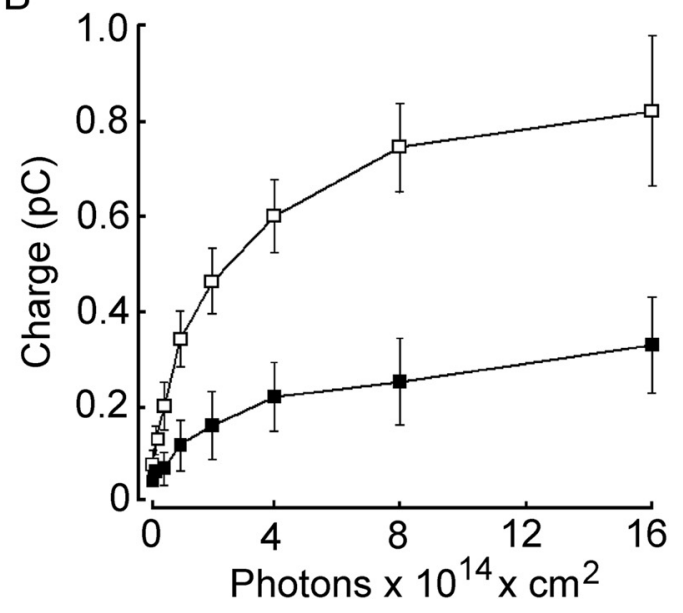

D

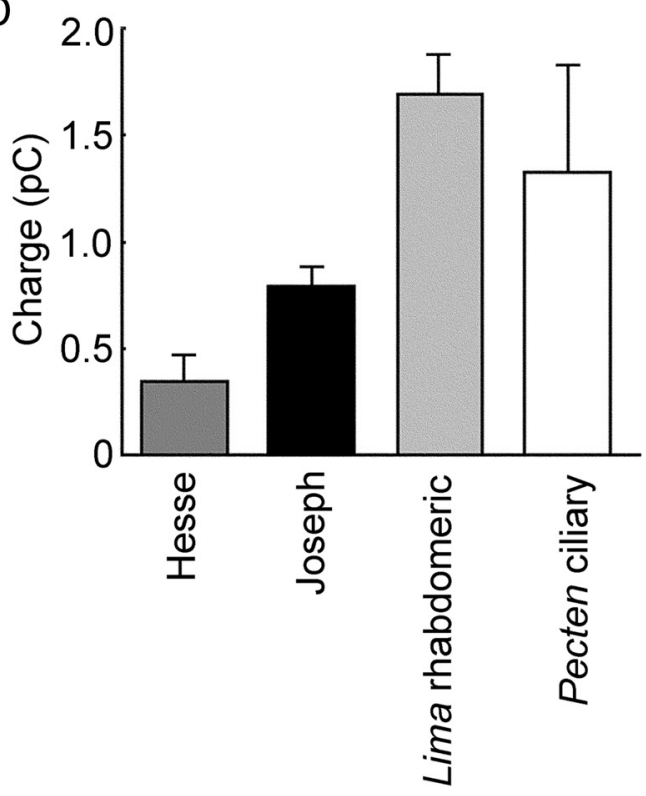

Figure 7. Functional quantification of melanopsin expression. $A$, Separation of the ERC from the photocurrent by equimolar substitution of extracellular Na with NMDG and depolarization of the membrane to $-30 \mathrm{mV}$. The late photocurrent is virtually eliminated, whereas the rapid outward component survives. $\boldsymbol{B}$, Average charge displacement as a function of light intensity, obtained by integration of the ERC. Open symbols, Joseph cells ( $n=5-9$ per point). Filled symbols, Hesse cells ( $n=4-5$ per point). Error bars indicate SEM. C, Comparison of the saturating ERC in a Joseph cell, a rhabdomeric photoreceptor from Lima scabra, and a ciliary photoreceptor from Pecten irradians. $D$, Average charge displacement in the two amphioxus microvillar photoreceptor types (Hesse, $n=$ 9; Joseph, $n=20)$ and in visual cells isolated from the retina of $\operatorname{Lima}(n=11)$ and Pecten $(n=6)$.

this lineage of photoreceptors for controlling physiological functions that depend on the sheer mean level of ambient illumination clearly must relax some of the requirements that would instead be crucial for visually guided behavior and calls for different functional features (Do et al., 2009). Certainly, one would expect that, for photoentrainment of circadian rhythms, long integration times (with the consequent loss of temporal resolution) would enhance reliability, whereas the capability to respond to low light intensity could actually turn into a disadvantage.

Our observations indicate that, in amphioxus, the peak amplitude of the membrane current per absorbed photon is similar to mammalian ipRGCs (Do et al., 2009). However, unlike mouse circadian receptors, in which unitary responses decay with time constants on the order of seconds, amphioxus quantum bumps are quite brief, in the millisecond range, as one would expect from the rapid time course of the macroscopic photocurrent [with durations that can be $<50 \mathrm{~ms}$ (Figure $6 \mathrm{~A}$ ), it is possibly the fastest light response reported to date].

Despite being on all other accounts bona fide rhabdomeric photoreceptors, the single-photon responses of Hesse and Joseph cells are substantially smaller than the quantum bumps recorded in arthropods [Drosophila, $\sim 10$ pA (Hardie, 1991; Henderson et al., 2000); Limulus, >500 pA (Kirkwood and Lisman, 1994)] and mollusks [Pecten, $\sim 40$ pA (Gomez and Nasi, 1997)]. Such limited gain can arise either because the number of ion channels recruited for each activated melanopsin is small or because of a low effective conductance of the individual channels and/or low probability of opening. This issue could be addressed by resolving light-dependent single-channel currents and comparing them with single-photon macroscopic responses. Measurements of light-activated unitary currents, although challenging, could be obtained in both the cell-attached and excised-patch configura- 
tions; in the latter case, despite the brief survival of light responses, the task of determining current amplitudes was aided by the fact that channel openings were somewhat longer. Singlechannel conductance turned out to be similar to that of the lightactivated channels described in arthropods (Bacigalupo and Lisman, 1983; Nagy and Stieve, 1990) and mollusks (Nasi and Gomez, 1992). Open-state durations were rapid, in the millisecond range, again not unlike those of invertebrate microvillar visual receptors. The similarity in unitary currents in the face of a considerably smaller single-photon macroscopic response implies that, in amphioxus, the number of ion channels activated per photoisomerization is low (perhaps as few as two to three); this stands in sharp contrast with canonical rhabdomeric photoreceptors, in which the estimates range from $\sim 15$ in Drosophila (Henderson et al., 2000) to $>1000$ in Limulus (Bacigalupo and Lisman, 1983). Such meager recruitment of light-dependent channels per effective photon in amphioxus, in turn, could stem from scarcity of either the channels themselves or the amount of internal transmitter mobilized to gate them when a photopigment molecule is activated. To answer such questions, it is instructive to compare the photoconductance density with that of invertebrate visual receptors. The saturating amplitude of lightevoked currents in amphioxus can approach $5 \mathrm{nA}$; considering that the average membrane capacitance has been measured at $\sim 120 \mathrm{pF}$ (Gomez et al., 2009), this gives an estimated current density on the order of $40 \mathrm{pA} / \mathrm{pF}$. Such a figure compares favorably with Limulus ( $150 \mathrm{pA} / \mathrm{pF}$; Brown and Coles, 1979), Drosophila ( $150 \mathrm{pA} / \mathrm{pF}$; Hardie, 1991), and Lima ( 40 pA/pF; Nasi, 1991a, 1991b). In other words, the availability of lightactivated channels is not the limiting factor in amphioxus; rather, the modest amplification factor must stem from a low biochemical gain, referring to the number of signaling molecules generated downstream of the isomerized photopigment.

Amphioxus single-photon response size is close to that measured in murine ipRGSs (Do et al., 2009). This implies that, if Joseph and Hesse cells can indeed be regarded as representing an ancestral form of the circadian photoreceptors of mammals, the moderate phototransduction gain in this lineage of light sensors was already evident at the pre-chordate level. Nonetheless, the overall light sensitivity of amphioxus microvillar photoreceptors remains much greater than in mammalian circadian photoreceptors, which prompted the question of the mechanistic basis of this discrepancy. One obvious candidate is photon-capturing ability. In Joseph and Hesse cells, the abundance of melanopsin is sufficient to produce readily measurable ERCs in response to bright lights, with magnitudes approaching those measured in vertebrate cones (Hestrin and Korenbrot, 1990; Makino et al., 1991), in which rhodopsin has been estimated at $\sim 10^{8} /$ cell (Hodgkin and Obryan, 1977), similar to the amount found in rods (Lyubarsky et al., 2004). In contrast, in murine ipRGCs, the level of photopigment expression, as derived from physiological measurements, is extremely reduced (Do et al., 2009): the estimated density is $\sim 10,000$-fold lower than that of rods and cones, which would certainly preclude recording an ERC in individual cells. This buttresses the notion that, in amphioxus, melanopsin must be quite abundant compared with ipRGCs. Such an amount could be quantified from the ERC knowing the charge displaced per photoisomerization. This parameter has been estimated for various photopigments: Hodgkin and Obryan (1977) used intracellular measurements of ERP to obtain a figure of $0.07 e$ in turtle red cones in situ. Patch-clamp recording of membrane current in different classes of dissociated salamander cones yielded estimates ranging from $0.08 e$ (Hestrin and Korenbrot, 1990) to $0.18 e$
(Makino et al., 1991). In rods, such determinations are more challenging because most of the rhodopsin is not located in the plasma membrane (in which it can make a large contribution to the ERP) but resides intracellularly within the disks; nonetheless, analysis of extracellular potentials in mammalian retinae again indicated that $0.2 e$ are translocated per photoisomerization (Hochstrate et al., 1982). Although these calculations entail a margin of uncertainty because they rely on estimates of pigment density and in some cases also of membrane capacitance-which were not determined concurrently in the same cells-the agreement is remarkable. In invertebrates, an estimate of the charge transferred per isomerized rhodopsin has been derived from a comparison of the ERP and the predicted number of rhodopsins stimulated, based in turn on extrapolated quantum bumps rates. This approach, which does not depend of information on actual levels of rhodopsin expression, yielded a figure of 0.13-0.17 electronic charges for Limulus ventral photoreceptors (Lisman and Bering, 1977). Overall, the conservation across widely divergent species and photopigments is quite striking, suggesting that melanopsin is likely to be in the same range. Taking a value of $0.14 e$, representing the approximate average of published estimates, one can use it to convert the saturating charge displacement measured in amphioxus photoreceptors into an approximate number of total functional melanopsin molecules. The results indicate that there are $\sim 20 \times 10^{6}$ photopigment molecules in Hesse cells and $\sim 33 \times 10^{6}$ in Joseph cells. Such expression levels, although shy by a factor of $\sim 2-4$ with respect to conventional visual receptors of similar size, is still more than three orders of magnitude above those inferred for vertebrate ipRGS. No doubt, the high levels of melanopsin expression must relate to the persistence of the microvillar architecture in amphioxus, which is instead lost in ipRGCs: one can speculate that, as the need for massive packing of photopigment was removed, the extensive infolding of the light-sensitive membrane would no longer be called for.

In summary, the design of the cellular and molecular machinery for light transduction in a lineage of photoreceptors is expected to undergo progressive modifications tailored to the required tasks. The light-sensing cells using r-opsin-type photopigment coupled to $G_{\mathrm{q}}$ (Arendt, 2003; Terakita, 2005) exhibit an extreme functional diversity: one end of the spectrum is epitomized by photoreceptors of insect eyes, with their high sensitivity and speed, geared to mediate visually guided rapid behavior (Laughlin and Weckström, 1993). At the other end stand the circadian receptors of mammals, in which the ongoing detailed characterization of their physiological properties has revealed a very low responsiveness to light and unusually slow kinetics, appropriate for tasks such as synchronizing the biological clock with the day/night cycle. Because Joseph and Hesse cells seem to constitute a link between the rhabdomeric photoreceptors already present in early bilateria and the ipRGCs of present-day vertebrates, they are poised to provide valuable evolutionary clues.

\section{References}

Angueyra JM, Pulido C, Malagón G, Nasi E, Gomez MdP (2012) Melanopsinexpressing amphioxus hotoreceptors transduce light via a phospholipase C signaling cascade. PLoS One 7:e29813. CrossRef Medline

Arendt D (2003) Evolution of eyes and photoreceptor cell types. Int J Dev Biol 47:563-571. Medline

Arendt D, Tessmar K, de Campos-Baptista MI, Dorresteijn A, Wittbrodt J (2002) Development of pigment-cup eyes in the polychaete Platynereis dumerilii and evolutionary conservation of larval eyes in Bilateria. Development 129:1143-1154. Medline 
Bacigalupo J, Lisman JE (1983) Single channel currents activated by light in Limulus ventral photoreceptors. Nature 304:268-270. CrossRef Medline

Baylor DA, Lamb TD, Yau KW (1979) Responses of retinal rods to single photons. J Physiol 288:613-634. Medline

Berson DM (2003) Strange vision: ganglion cells as circadian photoreceptors. Trends Neurosci 26:314-320. CrossRef Medline

Berson DM, Dunn FA, Takao M (2002) Phototransduction by retinal ganglion cells that set the circadian clock. Science 295:1070-1073. CrossRef Medline

Brown JE, Coles JA (1979) Saturation of the response to light in Limulus ventral photoreceptor. J Physiol 296:373-392. Medline

Cone RA (1967) Early receptor potential: photoreversible charge displacement in rhodopsin. Science 155:1128-1131. CrossRef Medline

Do MT, Kang SH, Xue T, Zhong H, Liao HW, Bergles DE, Yau KW (2009) Photon capture and signalling by melanopsin retinal ganglion cells. Nature 457:281-287. CrossRef Medline

Eakin RM, Westfall JA (1962) Fine structure of photoreceptors in Amphioxus. J Ultra Res 6:531-539. CrossRef Medline

Ertel EA (1990) Excised patches of plasma membrane from vertebrate rod outer segments retain a functional phototransduction enzymatic cascade. Proc Natl Acad Sci U S A 87:4226-4230. CrossRef Medline

Fuortes MG, Yeandle S (1964) Probability of occurrence of discrete potential waves in the eye of Limulus. J Gen Physiol 47:443-463. CrossRef Medline

Gomez MP, Nasi E (1994) The light-sensitive conductance of hyperpolarizing invertebrate photoreceptors: a patch-clamp study. J Gen Physiol 103: 939-956. CrossRef Medline

Gomez MP, Nasi E (1997) Light adaptation in Pecten hyperpolarizing photoreceptors: insensitivity to Ca manipulations. J Gen Physiol 109:371-384. CrossRef Medline

Gomez Mdel P, Angueyra JM, Nasi E (2009) Light-transduction in melanopsin-expressing photoreceptors of Amphioxus. Proc Natl Acad Sci U S A 106:9081-9086. CrossRef Medline

Graham DM, Wong KY, Shapiro P, Frederick C, Pattabiraman K, Berson DM (2008) Melanopsin ganglion cells use a membrane associated rhabdomeric phototransduction cascade. J Neurophysiol 99:2522-2532. CrossRef Medline

Hardie RC (1991) Whole-cell recordings of the light induced current in dissociated Drosophila photoreceptors: evidence for feedback by calcium permeating the light-sensitive channels. Proc R Soc Lond B 245:203-210. CrossRef

Henderson SR, Reuss H, Hardie RC (2000) Single photon responses in Drosophila photoreceptors and their regulation by $\mathrm{Ca}^{2+}$. J Physiol 524:179-194. CrossRef Medline

Hestrin S, Korenbrot JI (1990) Activation kinetics of retinal cones and rods: response to intense flashes of light. J Neurosci 10:1967-1973. Medline

Hochstrate P, Lindau M, Rüppel H (1982) On the origin and the signalshaping mechanism of the fast photosignal in the vertebrate retina. Biophys J 38:53-61. CrossRef Medline

Hodgkin AL, O'Bryan PM (1977) Internal recording of the early receptor potential in turtle cones. J Physiol 267:737-766. Medline

Kirkwood A, Lisman JE (1994) Determinants of single photon response variability. J Gen Physiol 103:679-690. CrossRef Medline

Koyanagi M, Terakita A (2008) Gq-coupled rhodopsin subfamily composed of invertebrate visual pigment and melanopsin. Photochem Photobiol 84:1024-1030. CrossRef Medline

Koyanagi M, Kubokawa K, Tsukamoto H, Shichida Y, Terakita A (2005) Cephalochordate melanopsin: evolutionary linkage between invertebrate visual cells and vertebrate photosensitive retinal ganglion cells. Curr Biol 15:1065-1069. CrossRef Medline
Laughlin SB, Weckström M (1993) Fast and slow photoreceptors-a comparative study of the functional diversity of coding and conductances in the Diptera. J Comp Physiol A Neuroethol Sens Neural Behav Physiol 172:593-609. CrossRef

Lisman JE, Bering H (1977) Electrophysiological measurement of the number of rhodopsin molecules in single Limulus photoreceptors. J Gen Physiol 70:621-633. CrossRef Medline

Lyubarsky AL, Daniele LL, Pugh EN Jr (2004) From candelas to photoisomerizations in the mouse eye by rhodopsin bleaching in situ and the light-rearing dependence of the major components of the mouse ERG. Vis Res 44:3235-3251. CrossRef Medline

Makino CL, Taylor WR, Baylor DA (1991) Rapid charge movements and photosensitivity of visual pigments in salamander rods and cones. J Physiol 442:761-780. Medline

Nagy K, Stieve H (1990) Light activated single channels currents in Limulus ventral nerve photoreceptors. Eur Biophys J 18:221-224.

Nakao T (1964) On the fine structure of the amphioxus photoreceptor. Tohoku J Exp Med 82:349-363. CrossRef Medline

Nasi E (1991a) Electrophysiological properties of isolated photoreceptors from the eye of Lima scabra. J Gen Physiol 97:17-34. CrossRef Medline

Nasi E (1991b) Two light-dependent conductances in the membrane of Lima photoreceptor cells. J Gen Physiol 97:55-72. CrossRef Medline

Nasi E, Gomez MP (1992) Light-activated ion channels in solitary photoreceptors from the eye of the scallop Pecten irradians. J Gen Physiol 99:747769. CrossRef Medline

Nasi E, Gomez MP (2009) Melanopsin-mediated light-sensing in amphioxus: a glimpse of the microvillar photoreceptor lineage within the deuterostomia. Commun Integr Biol 2:441-443. CrossRef

Peirson S, Foster RG (2006) Melanopsin: another way of signaling light. Neuron 49:331-339. CrossRef Medline

Provencio I, Jiang G, De Grip WJ, Hayes WP, Rollag MD (1998) Melanopsin: an opsin in melanophores, brain and eye. Proc Natl Acad Sci U S A 95:340-345. CrossRef Medline

Pulido C, Malagón G, Ferrer C, Chen JK, Angueyra JM, Nasi E, Gomez Mdel P (2012) The light-sensitive conductance of melanopsin-expressing Joseph and Hesse cells in amphioxus. J Gen Physiol 139:19-30. CrossRef Medline

Putnam NH, Butts T, Ferrier DE, Furlong RF, Hellsten U, Kawashima T, Robinson-Rechavi M, Shoguchi E, Terry A, Yu JK, Benito-Gutiérrez EL, Dubchak I, Garcia-Fernàndez J, Gibson-Brown JJ, Grigoriev IV, Horton AC, de Jong PJ, Jurka J, Kapitonov VV, Kohara Y, Kuroki Y, et al. (2008) The amphioxus genome and the evolution of chordate karyotype. Nature 453:1064-1072. CrossRef Medline

Ruiz MS, Anadon R (1991) Some considerations on the fine structure of rhabdomeric photoreceptors in the amphioxus, Branchiostoma lanceolatum (Cephalochordata). J Hirnforsch 32:159-164. Medline

Schubert M, Escriva H, Xavier-Neto J, Laudet V (2006) Amphioxus and tunicates as evolutionary model systems. Trends Ecol Evol 21:269-277. CrossRef Medline

Sokabe M, Sachs F, Jing ZQ (1991) Quantitative video microscopy of patch clamped membranes: stress, strain, capacitance, and stretch channel activation. Biophys J 59:722-728. CrossRef Medline

Terakita A (2005) The opsins. Genome Biol 6:213. CrossRef Medline

Watanabe S, Matthews G (1988) Regional distribution of cGMP-activated ion channels in the plasma membrane of the rod photoreceptor. J Neurosci 8:2334-2337. Medline

Wong F, Knight BW, Dodge FA (1980) Dispersion of latencies in photoreceptors of Limulus and the adapting-bump model. J Gen Physiol 76:517537. CrossRef Medline 